\title{
Analysis of the Physiological Load on Lumbar Vertebrae in Patients with Osteoporosis: A Finite- element Study
}

Jong-Moon Hwang ( $\nabla$ hti82@knu.ac.kr)

School of Medicine, Kyungpook National University

\section{Sungwook Kang}

Korea Institute of Industrial Technology

Chan-Hee Park

Kyungpook National University Hospital

\section{Subum Lee}

Kyungpook National University Hospital

\section{Yu-Sun Min}

School of Medicine, Kyungpook National University

\section{Chul-Hyun Kim}

School of Medicine, Kyungpook National University

\section{Mingoo Cho}

Korea Institute of Industrial Technology

\section{Gu-Hee Jung}

College of Medicine, Gyeongsang National University

\section{Dong-Hee Kim}

College of Medicine, Gyeongsang National University

\section{Kyoung-Tae Kim}

School of Medicine, Kyungpook National University

\section{Research Article}

Keywords: Osteoporosis, Intervertebral disc, Vertebral body, Finite-element analysis, Lumbar spine

Posted Date: January 24th, 2022

DOI: https://doi.org/10.21203/rs.3.rs-1229870/v1

License: () (7) This work is licensed under a Creative Commons Attribution 4.0 International License. Read Full License 


\section{Abstract}

Purpose: This study aims to investigate the difference in physiological loading on the spine in three different motions (flexion-extension, lateral bending, and axial rotation) between osteoporotic and normal spines, using finite element modelling.

Methods: A three-dimensional finite element (FE) model centered on the lumbar spine was constructed. We applied two different material properties of osteoporotic and normal spines. For the FE analysis, three loading conditions (flexion-extension, lateral bending, and axial rotation) were applied.

Results: The load was higher on the nucleus pulposus at all vertebral levels in all movements, in the osteoporosis group than in the normal group. On the annulus fibrosus, the load increased at the level of L3L4, L4-L5, and L5-S in the flexion-extension group and at L4-L5 and L5-S levels in the lateral bending group. The values of flexion-extension and lateral bending increased in two motions in the L4 and L5 cortical bones and in axial rotation at the level of L5. Additionally, the load increased in the lower endplate of L5-S and L4-L5 in all movements, especially lateral bending. Even in the group with no increase, there was a part that received increased load locally for each element in the three-dimensional reconstructed view of the pressure distribution in color.

Conclusion: The load on the lumbar region in the three loading conditions, was greater in most components of osteoporotic vertebrae than in normal vertebrae and the value was highest in the nucleus pulposus. Considering the increase in the measured load and the local increase in the pressure distribution, we believe that these results can contribute to explaining discogenic pain and degeneration.

\section{Introduction}

Osteoporosis is a worldwide health problem of considerable magnitude. It is the most common cause of fractures and is estimated to affect 1.5 million individuals each year ${ }^{1}$. Moreover, the risk of fractures due to trauma increases in patients with preexisting osteoporosis ${ }^{2}$. Osteoporotic fractures are classified as vertebral or non-vertebral and occur most commonly in the hip, wrist, and humerus ${ }^{3}$. In Europe, according to the European Vertebral Osteoporosis Study (EVOS), the prevalence of osteoporosis is $12.2 \%$ among males and $12 \%$ in those aged between 50 and 79 years ${ }^{4}$. The annual incidence is $1 \%, 2 \%$, and $3 \%$ in women aged 65,75 , and 85 years, respectively. In males over 50 years of age, the prevalence ranges between 5.7 and 6.8/1,000 person/years, which is equivalent to approximately half of that seen in women ${ }^{5}$. Osteoporosis and poor bone health, similar to other chronic diseases, are increasingly becoming a burden on society.

Vertebral compression fractures are the most common type of osteoporotic fracture ${ }^{6}$. These may cause low back pain and limitation of daily life owing to pain, which can become chronic ${ }^{7}$. Management of chronic pain in patients with osteoporosis involves a combination of pharmacological and nonpharmacological therapies and exercises to improve axial stability ${ }^{8}$. However, since it is difficult to 
measure the difference in pressure within spinal structures, experimental studies on the difference in pressure distribution between normal and osteoporotic vertebrae have rarely been conducted.

We believe that the physical properties of the osteoporotic spine differ from those of the normal spine. As a result, the vertebral load is expected to be higher in the osteoporotic spine. This study aims to investigate the difference in physiological load on the spine with three different motions between osteoporotic and normal spines, using finite element modelling. To our knowledge, this is the first study evaluating this research hypothesis.

\section{Methods}

A three-dimensional (3D) finite element (FE) analysis was carried out to investigate the effects of various load modes (flexion-extension, lateral bending, and axial rotation) on the lumbar spine and disc, in normal and osteoporotic patients. The distribution of the calculated von Mises stress was observed by applying loads to a 3D finite element model, including the lumbar vertebrae and disc. This work was supported by the Biomedical Research Institute grant, Kyungpook National University Hospital (2021).

\section{Development of the FE model}

A 3D FE model centered on the lumbar spine was constructed. It comprised the sacrum, L1 to L5 lumbar vertebrae (including the cortical and cancellous bones and posterior element), intervertebral discs (including nucleus pulposus and annulus fibrosus), endplates, and facet joints, as shown in Figure 1. The posterior elements consisted of the pedicles, lamina, facets (articular process), and transverse and spinous processes. The end plate was a bilayer of cartilage and bone that separated the intervertebral discs from the adjacent vertebrae. The 3D FE model was completed by converting the surface model into a solid model using CT data. Model conversion was performed using the 3D computer-aided design (CAD) softwares, CATIA (Dassault Systèmes, Vélizy-Villacoublay, France) and ANSYS SpaceClaim, (SpaceClaim Corporation, Concord, MA, USA).

\section{Mesh and material properties for the FE model}

The mesh for the FE analysis was created using the Static Structural module of the ANSYS Workbench. The element size was determined through a sensitivity analysis of the mesh. For FE analysis, material properties such as the elastic modulus and Poisson's ratio of the components, are required ${ }^{9}$. These material properties differ in normal and osteoporotic patients; patients with osteoporosis have lower bone density than normal individuals. Therefore, the elastic modulus of components related to bone, such as the cortical, cancellous, and posterior parts of the vertebra, is small. In contrast, the modulus of elasticity of intervertebral discs is relatively larger in osteoporotic patients than in normal individuals. Information on the mesh and material properties for the FE model is summarized in Table $1^{10-12}$. 
Table 1

Information of mesh and material properties for the finite element model

\begin{tabular}{|c|c|c|c|c|c|c|c|}
\hline \multirow[t]{2}{*}{ Item } & \multirow[t]{2}{*}{$\begin{array}{l}\text { Number } \\
\text { of } \\
\text { Nodes }\end{array}$} & \multirow[t]{2}{*}{$\begin{array}{l}\text { Number } \\
\text { of } \\
\text { Elements }\end{array}$} & \multicolumn{2}{|c|}{$\begin{array}{l}\text { Elastic Modulus } \\
\mathrm{E}(\mathrm{MPa})\end{array}$} & \multicolumn{2}{|c|}{ Poisson's Ratio V } & \multirow[t]{2}{*}{ Reference } \\
\hline & & & Normal & Osteoporosis & Normal & Osteoporosis & \\
\hline $\begin{array}{l}\text { Cortical } \\
\text { bone }\end{array}$ & 69,667 & 37,138 & 12,000 & 8,040 & 0.3 & 0.3 & 11,12 \\
\hline $\begin{array}{l}\text { Cancellous } \\
\text { bone }\end{array}$ & 71,381 & 47,169 & 200 & 34 & 0.25 & 0.25 & 11,12 \\
\hline $\begin{array}{l}\text { Posterior } \\
\text { bone }\end{array}$ & 37,963 & 20,990 & 3,500 & 2,345 & 0.25 & 0.25 & 11,12 \\
\hline Endplate & 30,138 & 13,503 & 1,000 & 670 & 0.3 & 0.3 & 10,11 \\
\hline $\begin{array}{l}\text { Nucleus } \\
\text { pulposus }\end{array}$ & 346,396 & 239,611 & 1 & 9 & 0.49 & 0.4 & 10,11 \\
\hline $\begin{array}{l}\text { Annulus } \\
\text { fiber }\end{array}$ & 358,484 & 239,295 & 4.2 & 5 & 0.45 & 0.45 & 10,11 \\
\hline Facet joint & 1,842 & 474 & 11 & 11 & 0.4 & & 12 \\
\hline
\end{tabular}

\section{Loading and boundary conditions}

For the FE analysis, three loading conditions (flexion-extension, lateral bending, and axial rotation) were applied, as shown in Figure 2. A moment of $400 \mathrm{~N} \cdot \mathrm{m}$ was applied to the human body structure. The total degrees of freedom of the sacrum were fixed, and bonding contact conditions were applied to each component of the human body so that they did not separate from each other when a load was applied.

\section{Results}

\section{Von Mises stress in the spine FE Model}

The von Mises stress was compared with the average of each component volume. Tables 2 to 4 show the von Mises stress results for each loading mode. 
Table 2

von-Mises stress results for Flexion-Extension loading mode.

\begin{tabular}{|c|c|c|c|c|}
\hline Component & $\begin{array}{l}\text { Lumbar } \\
\text { level }\end{array}$ & $\begin{array}{l}\text { Osteoporosis (A) } \\
(\mathrm{MPa})\end{array}$ & $\begin{array}{l}\text { Normal (B) } \\
(\mathrm{MPa})\end{array}$ & $\begin{array}{l}\text { Loading ratio } \\
\text { (A-B)/Bष100 } \\
\text { (\%) }\end{array}$ \\
\hline \multirow[t]{5}{*}{ Cortical bone } & L1 & 25.126 & 28.122 & -10.65 \\
\hline & L2 & 53.361 & 70.227 & -24.02 \\
\hline & L3 & 43.054 & 52.126 & -17.40 \\
\hline & L4 & 57.693 & 55.173 & $4.57^{\star}$ \\
\hline & L5 & 43.967 & 30.076 & $46.19^{*}$ \\
\hline \multirow[t]{5}{*}{ Cancellous bone } & L1 & 0.51006 & 1.2454 & -59.04 \\
\hline & L2 & 0.64338 & 2.4965 & -74.23 \\
\hline & L3 & 0.68258 & 2.2162 & -69.20 \\
\hline & L4 & 1.0499 & 2.3183 & -54.71 \\
\hline & L5 & 1.1709 & 1.6815 & -30.37 \\
\hline \multirow[t]{5}{*}{ Posterior bone } & L1 & 5.3673 & 13.053 & -58.88 \\
\hline & L2 & 7.6343 & 16.807 & -54.58 \\
\hline & L3 & 10.621 & 17.928 & -40.76 \\
\hline & L4 & 11.871 & 13.915 & -14.69 \\
\hline & L5 & 10.534 & 10.699 & -1.54 \\
\hline \multirow[t]{5}{*}{ Lower endplate } & L1-L2 & 56.732 & 82.265 & -31.04 \\
\hline & L2-L3 & 47.543 & 70.456 & -32.52 \\
\hline & L3-L4 & 33.017 & 48.089 & -31.34 \\
\hline & L4-L5 & 24.117 & 26.97 & -10.58 \\
\hline & L5-S & 8.424 & 5.8443 & $44.14^{*}$ \\
\hline \multirow[t]{5}{*}{ Upper endplate } & L1-L2 & 44.762 & 64.95 & -31.08 \\
\hline & L2-L3 & 67.358 & 100.08 & -32.70 \\
\hline & L3-L4 & 47.912 & 69.273 & -30.84 \\
\hline & L4-L5 & 46.778 & 63.812 & -26.69 \\
\hline & L5-S & 26.971 & 30.933 & -12.81 \\
\hline
\end{tabular}




\begin{tabular}{|c|c|c|c|c|}
\hline Component & $\begin{array}{l}\text { Lumbar } \\
\text { level }\end{array}$ & $\begin{array}{l}\text { Osteoporosis (A) } \\
(\mathrm{MPa})\end{array}$ & $\begin{array}{l}\text { Normal (B) } \\
(\mathrm{MPa})\end{array}$ & $\begin{array}{l}\text { Loading ratio } \\
\text { (A-B)/Bष100 } \\
\text { (\%) }\end{array}$ \\
\hline \multirow[t]{5}{*}{ Annulus fiber } & L1-L2 & 1.5629 & 2.0654 & -24.33 \\
\hline & L2-L3 & 2.6575 & 3.4548 & -23.08 \\
\hline & L3-L4 & 3.2907 & 3.0178 & $9.04^{*}$ \\
\hline & L4-L5 & 5.7342 & 5.3602 & $6.98^{*}$ \\
\hline & L5-S & 6.5444 & 5.818 & $12.49^{*}$ \\
\hline \multirow[t]{5}{*}{ Nucleus pulposus } & L1-L2 & 2.1013 & 0.46321 & $353.64^{*}$ \\
\hline & L2-L3 & 3.2781 & 1.8385 & $78.3^{*}$ \\
\hline & L3-L4 & 3.3553 & 1.8947 & $77.09^{*}$ \\
\hline & L4-L5 & 4.2502 & 1.3132 & $223.65^{\star}$ \\
\hline & L5-S & 4.8262 & 1.5877 & $203.97^{\star}$ \\
\hline
\end{tabular}


Table 3

von-Mises stress results for Lateral bending loading mode.

\begin{tabular}{|c|c|c|c|c|}
\hline Component & $\begin{array}{l}\text { Lumbar } \\
\text { level }\end{array}$ & $\begin{array}{l}\text { Osteoporosis (A) } \\
(\mathrm{MPa})\end{array}$ & $\begin{array}{l}\text { Normal (B) } \\
(\mathrm{MPa})\end{array}$ & $\begin{array}{l}\text { Loading ratio } \\
\text { (A-B)/B囚100 (\%) }\end{array}$ \\
\hline \multirow[t]{5}{*}{ Cortical bone } & L1 & 13.497 & 16.516 & -18.28 \\
\hline & L2 & 32.68 & 45.26 & -27.79 \\
\hline & L3 & 37.049 & 41.368 & -10.44 \\
\hline & L4 & 52.804 & 47.511 & $11.14^{\star}$ \\
\hline & L5 & 46.602 & 31.986 & $45.69 *$ \\
\hline \multirow[t]{5}{*}{ Cancellous bone } & L1 & 0.12077 & 0.39291 & -69.26 \\
\hline & L2 & 0.29689 & 0.90154 & -67.07 \\
\hline & L3 & 0.6554 & 1.4151 & -53.69 \\
\hline & L4 & 0.29689 & 1.8355 & -83.83 \\
\hline & L5 & 0.12077 & 2.1061 & -94.27 \\
\hline \multirow[t]{5}{*}{ Posterior bone } & L1 & 3.418 & 8.6089 & -60.30 \\
\hline & L2 & 4.2622 & 8.6113 & -50.50 \\
\hline & L3 & 6.8846 & 11.261 & -38.86 \\
\hline & L4 & 9.1897 & 10.523 & -12.67 \\
\hline & L5 & 15.874 & 18.713 & -15.17 \\
\hline \multirow[t]{5}{*}{ Lower endplate } & L1-L2 & 40.946 & 64.309 & -36.33 \\
\hline & L2-L3 & 38.612 & 61.885 & -37.61 \\
\hline & L3-L4 & 25.25 & 37.471 & -32.61 \\
\hline & L4-L5 & 19.487 & 18.555 & $5.02^{\star}$ \\
\hline & L5-S & 7.6198 & 6.0725 & $25.48^{*}$ \\
\hline \multirow[t]{5}{*}{ Upper endplate } & L1-L2 & 32.16 & 49.854 & -35.49 \\
\hline & L2-L3 & 52.787 & 83.705 & -36.94 \\
\hline & L3-L4 & 39.689 & 60.355 & -34.24 \\
\hline & L4-L5 & 37.619 & 49.207 & -23.55 \\
\hline & L5-S & 19.313 & 20.299 & -4.86 \\
\hline Annulus fiber & L1-L2 & 1.7252 & 3.2563 & -47.02 \\
\hline
\end{tabular}




\begin{tabular}{|c|c|c|c|c|}
\hline Component & $\begin{array}{l}\text { Lumbar } \\
\text { level }\end{array}$ & $\begin{array}{l}\text { Osteoporosis (A) } \\
\text { (MPa) }\end{array}$ & $\begin{array}{l}\text { Normal (B) } \\
(\mathrm{MPa})\end{array}$ & $\begin{array}{l}\text { Loading ratio } \\
\text { (A-B)/Bष100 (\%) }\end{array}$ \\
\hline & L2-L3 & 2.8048 & 4.6763 & -40.02 \\
\hline & L3-L4 & 4.4374 & 5.293 & -16.16 \\
\hline & L4-L5 & 5.5855 & 5.5839 & $0.03^{*}$ \\
\hline & L5-S & 5.7893 & 5.6254 & $2.91^{*}$ \\
\hline \multirow[t]{5}{*}{ Nucleus pulposus } & L1-L2 & 2.4159 & 0.69101 & $249.62^{*}$ \\
\hline & L2-L3 & 3.9118 & 0.9813 & $298.63^{*}$ \\
\hline & L3-L4 & 5.2183 & 1.1694 & $346.24^{\star}$ \\
\hline & L4-L5 & 4.3405 & 1.4543 & $198.46^{\star}$ \\
\hline & L5-S & 4.5578 & 1.3158 & $246.39^{*}$ \\
\hline
\end{tabular}


Table 4

von-Mises stress results for Axial rotation loading mode.

\begin{tabular}{|c|c|c|c|c|}
\hline Component & $\begin{array}{l}\text { Lumbar } \\
\text { level }\end{array}$ & $\begin{array}{l}\text { Osteoporosis (A) } \\
(\mathrm{MPa})\end{array}$ & $\begin{array}{l}\text { Normal (B) } \\
(\mathrm{MPa})\end{array}$ & $\begin{array}{l}\text { Loading ratio } \\
\text { (A-B)/Bष100 } \\
\text { (\%) }\end{array}$ \\
\hline \multirow[t]{5}{*}{ Cortical bone } & L1 & 1.7847 & 2.9347 & -39.19 \\
\hline & L2 & 5.559 & 9.1105 & -38.98 \\
\hline & L3 & 3.6444 & 6.1652 & -40.89 \\
\hline & L4 & 4.8083 & 8.3163 & -42.18 \\
\hline & L5 & 43.408 & 41.068 & $5.7^{*}$ \\
\hline \multirow[t]{5}{*}{ Cancellous bone } & L1 & 0.0151 & 0.0633 & -76.15 \\
\hline & L2 & 0.0306 & 0.14743 & -79.24 \\
\hline & L3 & 0.0313 & 0.15748 & -80.12 \\
\hline & L4 & 0.0235 & 0.11987 & -80.40 \\
\hline & L5 & 0.61867 & 1.598 & -61.28 \\
\hline \multirow[t]{5}{*}{ Posterior bone } & L1 & 0.11104 & 0.28003 & -60.35 \\
\hline & L2 & 0.31113 & 0.59648 & -47.84 \\
\hline & L3 & 0.64636 & 1.3479 & -52.05 \\
\hline & L4 & 0.94167 & 1.9366 & -51.38 \\
\hline & L5 & 38.26 & 47.385 & -19.26 \\
\hline \multirow[t]{5}{*}{ Lower endplate } & L1-L2 & 9.6145 & 16.477 & -41.65 \\
\hline & L2-L3 & 6.1934 & 10.881 & -43.08 \\
\hline & L3-L4 & 5.9779 & 10.619 & -43.71 \\
\hline & L4-L5 & 7.0101 & 9.6956 & -27.70 \\
\hline & L5-S & 7.5692 & 5.3671 & $41.03^{*}$ \\
\hline \multirow[t]{4}{*}{ Upper endplate } & L1-L2 & 6.7984 & 11.463 & -40.69 \\
\hline & L2-L3 & 8.3617 & 14.076 & -40.60 \\
\hline & L3-L4 & 4.2539 & 7.4382 & -42.81 \\
\hline & L4-L5 & 6.0596 & 10.761 & -43.69 \\
\hline
\end{tabular}




\begin{tabular}{|c|c|c|c|c|}
\hline \multirow[t]{2}{*}{ Component } & $\begin{array}{l}\text { Lumbar } \\
\text { level }\end{array}$ & $\begin{array}{l}\text { Osteoporosis (A) } \\
(\mathrm{MPa})\end{array}$ & $\begin{array}{l}\text { Normal (B) } \\
(\mathrm{MPa})\end{array}$ & $\begin{array}{l}\text { Loading ratio } \\
\text { (A-B)/Bष100 } \\
(\%)\end{array}$ \\
\hline & L5-S & 14.466 & 16.651 & -13.12 \\
\hline \multirow[t]{5}{*}{ Annulus fiber } & L1-L2 & 0.0386 & 0.0688 & -43.90 \\
\hline & L2-L3 & 0.12801 & 0.26926 & -52.46 \\
\hline & L3-L4 & 0.14739 & 0.2947 & -49.99 \\
\hline & L4-L5 & 0.26848 & 0.43696 & -38.56 \\
\hline & L5-S & 7.301 & 8.3341 & -12.40 \\
\hline \multirow[t]{5}{*}{ Nucleus pulposus } & L1-L2 & 0.0303 & 0.0152 & $99.34^{*}$ \\
\hline & L2-L3 & 0.10799 & 0.055 & $96.35^{*}$ \\
\hline & L3-L4 & 0.12821 & 0.058 & $121.05^{\star}$ \\
\hline & L4-L5 & 0.30552 & 0.0769 & $297.3^{*}$ \\
\hline & L5-S & 7.6572 & 1.587 & $382.5^{\star}$ \\
\hline
\end{tabular}

We compared the load on each component at each level of the lumbar spine between the osteoporosis and normal groups. The ratio of the load difference, expressed as a percentage, was calculated using the formula $(A-B) / B \star 100(\%)$, where $A$ and $B$ represent the osteoporotic and normal groups, respectively. $A$ positive value denotes that the osteoporosis group takes more load than the normal group.

Comparing the osteoporosis and normal groups in the flexion-extension action group, the values of L4 and L5 cortical bones as per the above formula were $4.57 \%$ and $46.19 \%$, respectively, indicating that the load increased by this value in osteoporosis. The cancellous and posterior bones and the upper endplate, did not differ between the two groups. In the lower endplate of L5-S, the load increased by $44.14 \%$ in osteoporosis. In addition, L3-L4, L4-L5, and L5-S annulus fibers in the osteoporosis group had loads higher by $9.04 \%$, $6.98 \%$, and $12.49 \%$, respectively. At all levels from L1-L2 to L5-S, the loads on the nucleus pulposus increased by $353.64 \%, 78.3 \%, 77.09 \%, 223.65 \%$, and $203.97 \%$, respectively.

In the lateral bending motion group, the load in the osteoporosis group increased to $11.14 \%$ and $45.69 \%$ in the cortical bone of L4 and L5, respectively, and to $5.02 \%$ and $25.48 \%$ in the lower endplate of the L4-L5 and L5-S, respectively. In addition, the loads on L4-L5 and L5-S annulus fibers increased slightly by $0.03 \%$ and $2.91 \%$, respectively, and across all levels, the load on the nucleus pulposus increased by $249.62 \%$, $298.63 \%, 346.24 \%, 198.46 \%$, and $246.39 \%$, in the osteoporosis group. 
Finally, in the axial rotation group, the load on the cortical bone of L5 in the osteoporosis group increased by $5.7 \%$ and that on the lower endplate of L5-S increased by $41.03 \%$. As in the other motions, the load in the nucleus pulposus at all lumbar levels, increased by $99.34 \%, 96.35 \%, 121.05 \%, 297.3 \%$, and $382.5 \%$, respectively. There were no differences between the two groups with respect to the annulus fibrosus, including the cancellous and posterior bones and the upper endplate.

All three motions, flexion-extension, lateral bending and axial rotation, had the largest absolute values in the nucleus pulposus at all lumbar spine levels, suggesting that it bore a large load in osteoporosis. In particular, the values were large in the flexion-extension and lateral bending motions and relatively small during axial rotation.

We also reconstructed the above results in 3D and expressed the difference in load distribution of the entire part including the surface, in color. Figure 3 shows an analysis of the cortical bone. Looking at L4 and L5 in the above results, which show that more load is received in osteoporosis, it was confirmed that the value of the load corresponding to red at a specific part of the interface, was high. In the results of the table above (even from L1 to L3, which had a positive value), there was a specific part in which the load corresponding to red was increased. Figure 4 shows the load distribution for the intervertebral discs, including the annulus fibrosus and nucleus pulposus. Regarding the cortical bone, it can be seen from the image that there is a partially increased part even in the group where the calculated load value does not appear to have increased.

\section{Discussion}

In this study, FE analysis was used to compare the von Mises stresses on the lumbar spine and intervertebral discs when various load-modes were applied to normal and osteoporotic spines. The cortical bone had the greatest von Mises stress, that is, the load was found to be concentrated on the cortical bone that supports the body structure. In particular, the largest von Mises stress occurs at L4 and L5, and it can be seen that in patients with osteoporosis, the stress is greater than that in normal persons at the corresponding positions (L4 and L5). In the nucleus pulposus, it was confirmed that patients with osteoporosis had $77.09-382.50 \%$ greater von Mises stress than those without. However, because the results shown in Tables 2 to 4 are based on the total value for each part, there is a limitation in that the load increase in specific parts cannot be reflected, as shown in figures 3 and 4 . In other words, even if it has a positive value, it can be compensated for by a sufficiently negative value, meaning that more load is applied if a specific part is coordinated. Therefore, the table value and 3D load distribution in color should be simultaneously compared, and the fact that a positive value does not indicate less load should not be overlooked. As shown in Figures 3 and 4, the fact that the osteoporosis group had a higher load on the surface bordering other adjacent sites may help explain the mechanism by which the following phenomena occur. First, it will be helpful to explain the mechanisms by which (a) osteophyte develops in the spine secondary to degeneration, and (b) intervertebral disc degeneration results in discogenic pain ${ }^{13-15}$. In other words, in osteoporotic patients, the load on the nucleus pulposus is more concentrated than that in normal individuals, which can accelerate disc degeneration ${ }^{16,17}$. 
Furthermore, several studies have shown that chronic back pain is caused by spinal deformity or kyphosis in patients with osteoporosis; furthermore, chronic low back pain tends to improve with pharmacological treatment of osteoporosis. According to our experimental model, this result can be explained by the difference in stress applied to each part in osteoporotic patients. These results further suggest a potential reduction in the incidence of vertebral fractures after proper treatment for osteoporosis in such patients. According to previous studies, pharmacological treatment is effective in preventing osteoporotic fractures 18. Based on our research, we believe that the pharmacological treatment of osteoporosis will help prevent fractures by affecting the physical properties of each element of the spine analyzed above, leading to a reduction in the load on each element.

This study has several limitations. First, the incidence of osteoporotic vertebral fractures is highest in the lower thoracic (T11 and T12) and upper lumbar (L1) vertebrae ${ }^{7}$. However, this study was conducted only on the lumbar spine, which, while advantageous for controlling variables, excludes the thoracic spine. Second, our FE model did not include tendons, nerves, ligaments, and muscles, and did not reflect the variability of these structures between the two groups and for each motion. However, the effect of the structures was minimized through comparative analysis, with the results obtained by including the structures above ${ }^{19}$. In addition, the differences in intervertebral disc height or physical properties were not reflected in the performance of each motion. Third, because this study is a model-based analysis, it is limited in that it does not reflect the actual clinical characteristics and risk factors of osteoporosis.

Although it was based on the physical properties of each component in osteoporosis, as presented in Table 1 , it is difficult to accurately represent the condition of the individual spine in clinical practice. As mentioned above, structural differences such as bony spur or disc degeneration, are often accelerated when osteoporosis is already present, but it is difficult to fully reflect these factors in a single model. In addition, it does not reflect the risk factors related to osteoporosis, such as age, low body weight, glucocorticoid therapy, current cigarette smoking, excessive alcohol consumption, previous fracture, and secondary osteoporosis ${ }^{20,21}$.

\section{Conclusion}

In conclusion, the load on the lumbar region in the three motions-flexion-extension, lateral bending, and axial rotation-was greater in most components of osteoporotic vertebrae, and the load was highest in the nucleus pulposus. According to the three-dimensionally reconstructed pressure distribution diagram, even in areas where the load did not increase, these factors may help explain the discogenic pain or degeneration occurring in osteoporosis, via a local increase in pressure in some regions.

\section{Declarations}

\section{Acknowledgements}

This work was supported by Biomedical Research Institute grant, Kyungpook National University Hospital (2021). 
The authors gratefully acknowledge the human data support provided by Korea Institute of Science \& Technology Information (KISTI) which produced these data with Catholic University of Medicine.

\section{Author contributions}

S.K., M.C., K.T.K. and J.M.H. planned the experiments. S.K. and M.C. performed processing of the model analysis. C.H.P. wrote original draft preparation. S.L., Y.S.M. and C.H.K. reviewed and edited the writing. G.H.J., D.H.K. and J.M.H. performed the data analysis. All authors have read and agreed to the published version of the manuscript.

\section{Competing interests}

The authors declare no competing interests.

\section{Data availability}

The datasets analyzed during the current study are available from the corresponding author on reasonable request.

\section{References}

1. General, O. o. t. S. Bone health and osteoporosis: a report of the Surgeon General. (2004).

2. Mackey, D. C. et al. High-trauma fractures and low bone mineral density in older women and men. Jama 298, 2381-2388 (2007).

3. Stone, K. L. et al. BMD at multiple sites and risk of fracture of multiple types: long-term results from the Study of Osteoporotic Fractures. Journal of Bone and Mineral Research 18, 1947-1954 (2003).

4. O'neill, T. et al. Reproducibility of a questionnaire on risk factors for osteoporosis in a multicentre prevalence survey: the European Vertebral Osteoporosis Study. International journal of epidemiology 23, 559-565 (1994).

5. Felsenberg, D. et al. Incidence of vertebral fracture in europe: results from the European Prospective Osteoporosis Study (EPOS). Journal of bone and mineral research: the official journal of the American Society for Bone and Mineral Research 17, 716-724 (2002).

6. Genant, H. K. et al. Interim report and recommendations of the World Health Organization task-force for osteoporosis. Osteoporosis international 10, 259 (1999).

7. Rosen, H. N. \& Walega, D. R. Osteoporotic thoracolumbar vertebral compression fractures: Clinical manifestations and treatment. Dostupno na: https://www. uptodate. com/contents/osteoporoticthoracolumbar-vertebralcompression-fractures-clinical-manifestations-and-treatment (2017).

8. Paolucci, T., Saraceni, V. M. \& Piccinini, G. Management of chronic pain in osteoporosis: challenges and solutions. Journal of pain research 9, 177 (2016). 
9. Kang, S. et al. The Effects of Paraspinal Muscle Volume on Physiological Load on the Lumbar Vertebral Column: A Finite-Element Study. Spine 46, E1015-E1021 (2021).

10. Byun, D.-H., Shin, D. A., Kim, J.-M., Kim, S.-H. \& Kim, H.-I. Finite element analysis of the biomechanical effect of coflex ${ }^{\mathrm{TM}}$ on the lumbar spine. Korean Journal of Spine 9, 131 (2012).

11. Cho, A.-R., Cho, S.-B., Lee, J.-H. \& Kim, K.-H. Effect of augmentation material stiffness on adjacent vertebrae after osteoporotic vertebroplasty using finite element analysis with different loading methods. Pain Physician 18, E1101-1110 (2015).

12. Park, W. M., Kim, K. \& Kim, Y. H. Effects of degenerated intervertebral discs on intersegmental rotations, intradiscal pressures, and facet joint forces of the whole lumbar spine. Computers in biology and medicine 43, 1234-1240 (2013).

13. Fujii, K. et al. Discogenic back pain: literature review of definition, diagnosis, and treatment. JBMR plus 3, e10180 (2019).

14. Peng, B. et al. The pathogenesis of discogenic low back pain. The Journal of bone and joint surgery. British volume 87, 62-67 (2005).

15. Pye, S. R. et al. Lumbar disc degeneration: association between osteophytes, end-plate sclerosis and disc space narrowing. Annals of the rheumatic diseases 66, 330-333 (2007).

16. Harada, A., Okuizumi, H., Miyagi, N. \& Genda, E. Correlation between bone mineral density and intervertebral disc degeneration. Spine 23, 857-861 (1998).

17. Tsouknidas, A., Sarigiannidis, S. O., Anagnostidis, K., Michailidis, N. \& Ahuja, S. Assessment of stress patterns on a spinal motion segment in healthy versus osteoporotic bony models with or without disc degeneration: a finite element analysis. The Spine Journal 15, S17-S22 (2015).

18. Jin, Y.Z., Lee, J. H., Xu, B. \& Cho, M. Effect of medications on prevention of secondary osteoporotic vertebral compression fracture, non-vertebral fracture, and discontinuation due to adverse events: a meta-analysis of randomized controlled trials. BMC musculoskeletal disorders 20, 1-17 (2019).

19. Mimura, M. et al. Disc degeneration affects the multidirectional flexibility of the lumbar spine. Spine 19, 1371-1380 (1994).

20. Lewiecki, E. M. \& Schmader, K. E. Osteoporotic fracture risk assessment. Cambridge, Massachusetts, EEUU. Obtenido de https://www. uptodate. com/contents/osteoporotic-fracture-riskassessment (2013).

21. Pisani, P. et al. Major osteoporotic fragility fractures: Risk factor updates and societal impact. World journal of orthopedics 7, 171 (2016).

\section{Figures}




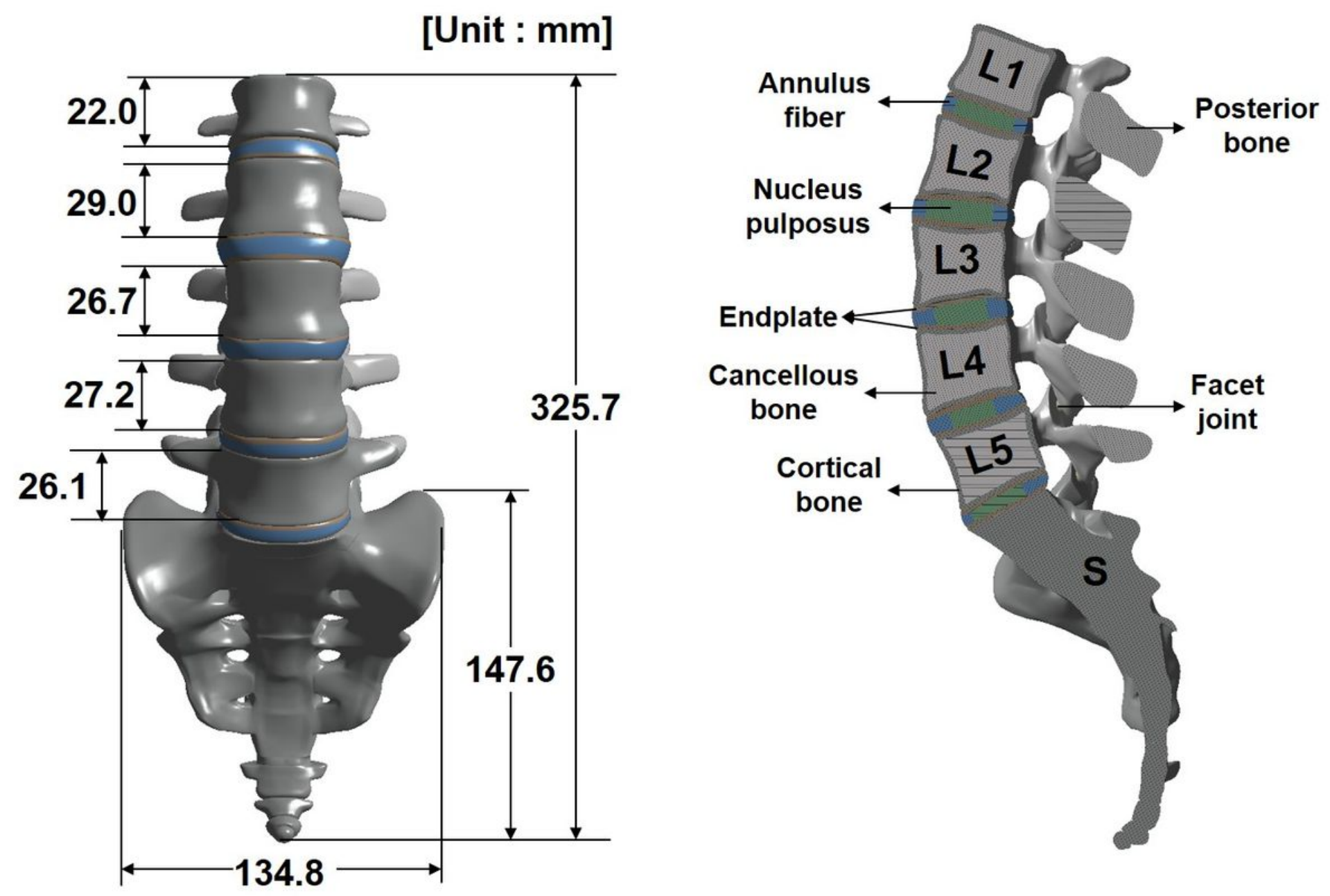

Figure 1

Results of analysis of loading on each vertebral level in flexion-extension. 


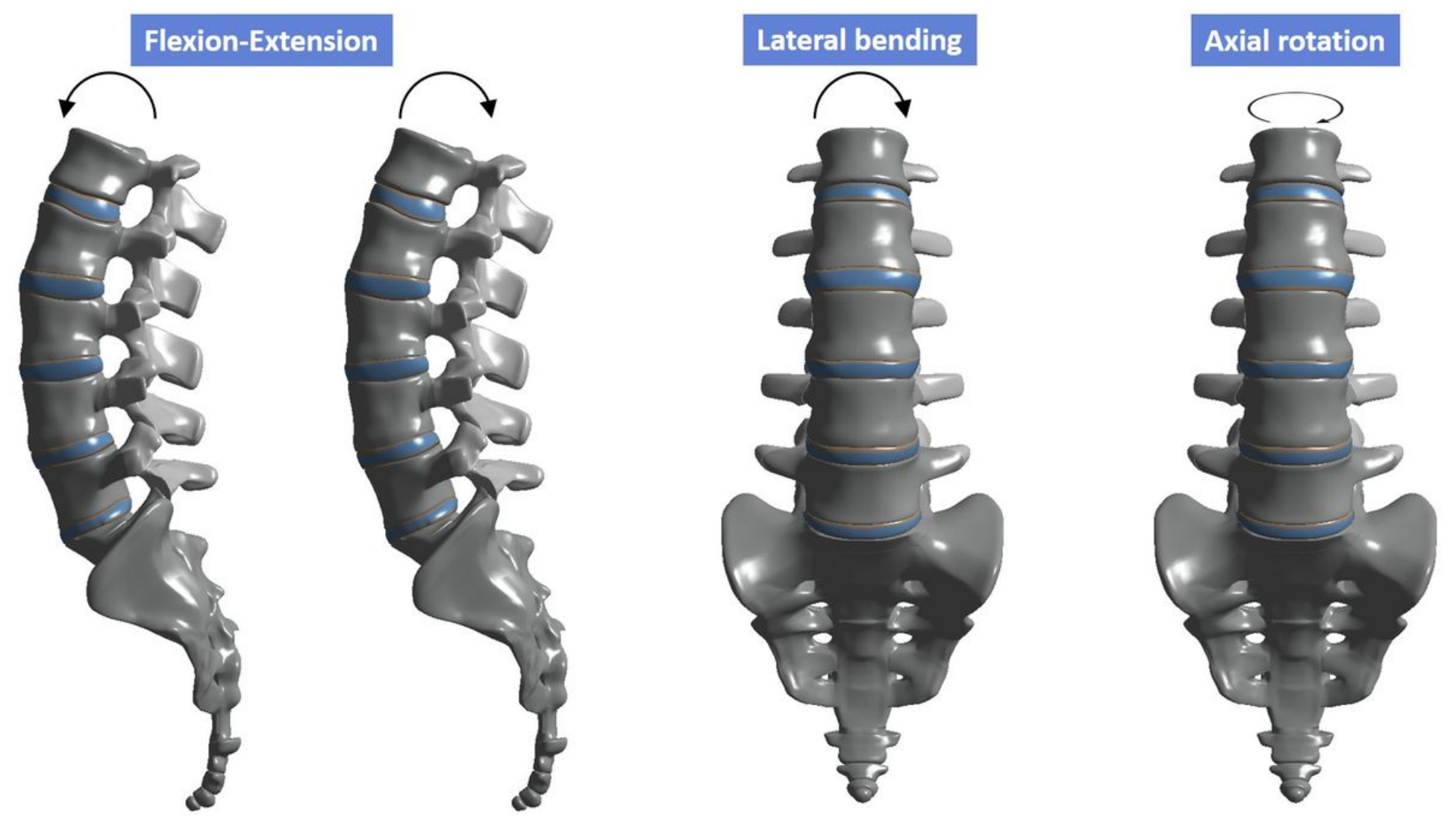

Figure 2

Three loading conditions (flexion-extension, lateral bending, and axial rotation)

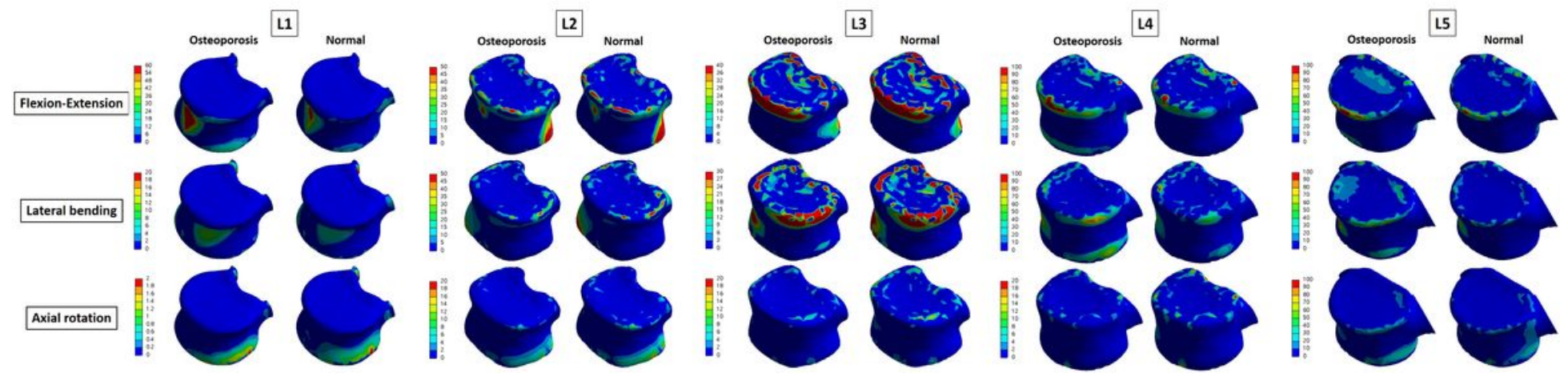

Figure 3

von-Mises Stress Results at cortical bone in three different motions (Unit: MPa).

Figure 4

(a): von Mises stress distribution on the intervertebral disc in flexion-extension loading mode. As a result of analysis in flexion-extension motion, the stress was concentrated in the annulus fibrosus of L3-L4, L4-L5 and L5-S, and in the nucleus of whole level of lumbar (Unit: MPa). 
(b): von Mises stress distribution on the intervertebral disc in lateral bending loading mode. As a result of analysis in lateral bending motion, the stress was concentrated in the annulus fibrosus of L4-L5 and L5-S, and in the nucleus of whole level of lumbar (Unit: MPa).

(c): von Mises stress distribution on the intervertebral disc in axial rotation loading mode. As a result of analysis in axial motion, the stress was mainly concentrated in the nucleus of whole level of lumbar (Unit: $\mathrm{MPa})$. 